\title{
COMMUNICATION BETWEEN NURSES AND DEAF PEOPLE IN HEALTH INSTITUTIONS
}

\author{
Marija Ljubicic, ${ }^{1}$ Sanda Zubcic, ${ }^{2}$ Sonja Sare ${ }^{3}$
}

\begin{abstract}
:
Introduction:: Upon arrival into a health institution, a deaf person is exposed to a higher stress level. They are at risk of receiving inadequate health care and health-related information due to limitations in communication between the deaf person and the health care workers. Despite the awareness of the presence of communication difficulties, research about the ways of communication between nurses and deaf people hasn't been sufficiently presented. This article focuses on the ways in which nurses and deaf people communicate, the difficulties in communication arising from that; emotional reactions and nurses' interest in the manual alphabet and sign language, and the perception about the need for an interpreter of sign language in a health institution.

Objectives: The primary objective of this cross-sectional study is to examine the difficulties in communication upon a deaf person's arrival into a health institution.

Methods: The original paper-and-pencil questionnaire for nurses includes questions about the communication problems upon the arrival of deaf people into health institutions. Differences between study variables were assessed for significance using the Mann-Whitney U test and Kruskal-Wallis test. The associations between variables were explored using Spearman rank correlation coefficients.

Results: The results show that $65 \%$ of the nurses think that the communication problem is strongly pronounced as the problem is the inability of deaf people to respond when called $(65 \%)$ and difficulties in understanding (40\%). The interest of nurses for problems of deaf people affects the manifestation of difficulties and the understanding of messages. The most frequent way of communication is showing $(95.1 \%)$ and writing $(62.5 \%)$. There is no significant difference in relation to age $(\mathrm{p}=0.103)$, sex $(\mathrm{p}=0.473)$, level of education $(\mathrm{p}=0.901)$ and the length of service $(\mathrm{p}=0.062)$.

Conclusion: The obtained results show how pronounced the communication difficulties between nurses and deaf people are. An interpreter in a health institution is necessary for effective communication. There is a high priority need for quality education of nurses about the ways of communicating with deaf people.
\end{abstract}

UDC Classification: 616-01; DOI: http://dx.doi.org/10.12955/cbup.v5.1052

Keywords: deaf people, nurses, communication, health institution

\section{Introduction}

Hearing impairment is the most common sensory disorder (Adib-Hajbaghery \& Rezaei-Shahsavarloo, 2015; Bennion \& Forshaw, 2013). The term "hearing impairment" or "hearing loss" means loss of function of varying intensity to all parts of the ear and the auditory pathway (Ljubičić, 2014). This impairment is the result of an illness or an injury ear canal and drum, middle ear, inner ear or of any localization of hearing aids. Because of limitations or barriers, people can be disabled in performing daily activities that are considered normal. (Mattjus, 2012). Depending on age, the level of development and the acquisition of speech, we can divide people with hearing impairment into prelingually and post-lingually deaf people (Ljubičić, 2014).

Communication problems are the most evident problems of these people. Due to difficulties in communication and the inadequate support of the environment, deaf people can feel excluded from the environment they live in (Hersh, 2013). Disrupted social interaction and social isolation are very common due to the feeling of discomfort of people because they believe that they have heard something wrong or to have talked about a wrong topic. The person can have emotional difficulties, be suspicious, frustrated, and angry due to the inability to hear (Ljubičić, 2014).

Upon arrival into a health institution, a deaf person is exposed to a higher stress level. They are at risk of receiving inadequate health care and health-related information because of limitations of communication between the deaf person and the health care workers (Chowdhry, Padhi, Mohanty, \& Biswal, 2016). Both, deaf persons and nurses face problems with information transfer, and the dissatisfaction of the deaf people and their family members. This results in different emotional reactions for deaf people and for nurses. The impossibility to hear a message, to respond, the lack of understanding of the staff, and numerous other problems can intensify communication problems and

\footnotetext{
${ }^{1}$ University of Zadar, General Hospital Zadar,Croatia, marija.ljubicic.zadar@ gmail.com

${ }^{2}$ General Hospital Zadar, Intensive Coronary Care Unit, Zadar, Croatia, sanda.culina@gmail.com

${ }^{3}$ University of Zadar, Medical School Ante Kuzmanica, Croatia, sonja.sare@gmail.com
} 
increase the sense of social isolation (Ljubičić, 2014). Also, the nurses encounter difficulties since there are sometimes different distracting factors that interfere with the communication process. The limited ability of deaf people to communicate and the not-providing of appropriate feedback from the nurse can negatively affect the active cooperation of the deaf person and the successful implementation of health care (Hornakova \& Hudakova, 2013).

There are four different ways of communication for deaf people: writing, lip reading, the manual alphabet, and sign language. (Ljubičić, 2014). A successful transfer of messages to deaf people depends on the methods of communication of the nurses. Most deaf people use lip-reading, speech or writing. Deaf people, who use writing, ask the nurse to write down the question, as well as to explain the orders they have received in writing (Ljubičić, 2014).

The effective communication between nurses and deaf persons is an essential element of nursing care, yet nursing education in how to communicate with deaf people is insufficient. The current nurse education in this field is mostly informative, which doesn't contribute to the development of competencies that are necessary for everyday practice. Nurses often communicate inappropriately, and lack the knowledge and skills to understand the communication needs of deaf person (Dickson \& Magovan, 2014). It is possible to look for reasons in the non-everyday need, the insufficient connection between theory and practice, but also in the insufficient sensitivity rising not only in general, but also in the scientific community for the needs of deaf people.

In order to minimize communication problems on both sides, it is necessary to elaborate in detail educational programs for nurses, with the emphasis on communication with deaf people. This is primarily important because the nurses are in a continuous contact with deaf people upon their arrival to a health institution and they can help to assure that deaf people receive proper quality care. Using good communication, nurses can provide effective health care for deaf people. (Newton \& Shah, 2013).

Despite the knowledge of the presence of communication difficulties, the research about the ways of communication between nurses and deaf people is not sufficiently presented. Also, even less presented are studies of the factors that complicate and/or don't allow for effective information transfer. Although practical experiences confirm the described issues, there is only a small amount of research to agree with this notion.

The aim of this study is to examine the frequency of encounters of nurses with deaf people; the ways of communication between nurses and deaf people, the difficulties in communication; emotional reaction and interest of nurses for the manual alphabet and sign language, as well as the perception of the need for an interpreter of sign language in a health institution.

\section{Methods}

Design and instrument

This is a cross-sectional study. The original paper-and-pencil questionnaire includes 30 items in total, divided into the before-mentioned groups related to communication and 4 particles of general data. The general data has been collected by entering the numeric value (age and the length of working experience of the respondents and by circling the offered answers (sex and the level of education). In specific data, the respondents indicated their level of agreement with statements using a Likert scale from 1 (completely disagree) to 5 (completely agree). We asked nurses about the ways and difficulties in the communication with deaf people (inability of deaf people to respond when called, understanding instructions and messages, and the lack of visible signs for deaf persons); emotional reactions of nurses when encountering the problem in communication such as concern, inconvenience, insecurity and anger. The statements include ways of communication with deaf people: showing, writing, speech, and the perception about the manual alphabet, sign language and an interpreter in the institution. This study was approved by the Human Research Ethics Committee General Hospital. Before filling out the survey, subjects were told about the purpose of the study; they were assured that the study was voluntary and that their responses would remain anonymous. Upon providing consent, subjects filled out the survey in individual cubicles to ensure privacy. 


\section{Participants}

The participants were 40 licensed nurses from 4 medical departments in one hospital in Croatia. Most of the participants were female $(95 \%)$, and $5 \%$ were male. The average age of the respondents was $36.9(\mathrm{SD} \pm 8.59 ; 95 \% \mathrm{CI}=34.13-39.62)$ years, the age range varied from 24 to 62 years. The average length of service is 16.3 ( $\mathrm{SD} \pm 8.56 ; 95 \% \mathrm{CI}=13.38$-18.86) years; the range was from 3 to 42 years. The level of education attained was high school for $80 \%$ for the nurses and university for $20 \%$.

Data analysis

The collected information has been processed with the MedCalc Statistical Software version 14.8.1 (Ostend, Belgium; 2014). The descriptive statistics include the distribution of frequencies, measures of central tendency and dispersion of results. The differences between variables were assessed using the Mann-Whitney U test and Kruskal-Wallis test. The associations between variables were explored using Spearman rank correlation coefficients. In the mentioned processing, values $p<0.05$ have been considered as statistically significant.

\section{Results}

In the analysis of the frequency of encounters of nurses and deaf people, the nurses declare that they are not often able to communicate with a deaf person in $62.5 \%$ of all answers, $20 \%$ can't assess it and $17.5 \%$ of them often communicate with deaf people. The encounters of nurses with deaf people is does not occur often $(\mathrm{M}=2.28 ; \mathrm{SD}=1.06 ; 95 \% \mathrm{CI}=1.94-2.61)$.

In the analysis which age group has the most encounters with deaf people, it can be noticed that it is mostly nurses with 6 to 10 years working experience, but the obtained difference in ranking of higher values is random, a statistically significant difference $(\mathrm{p}=0.210)$ hasn't been established.

There is no significant difference in age $(\mathrm{p}=0.232)$, sex $(\mathrm{p}=0.400)$ and level of education $(\mathrm{p}=0.561)$. Even $27.5 \%$ nurses are unable to immediately estimate that a person has a hearing impairment, $25 \%$ cannot assess it and $47.5 \%$ can immediately assess that a person has a hearing impairment $(\mathrm{M}=2.70$; $\mathrm{SD}=1.20 ; 95 \% \mathrm{CI}=2.32-3.08$ ). In order to improve message transfer, $87.5 \%$ of nurses ask the deaf person to write down what they need $(\mathrm{M}=4.00 ; \mathrm{SD}=0.91 ; 95 \% \mathrm{CI}=3.71-4.29)$.

Despite that, $47.5 \%$ of nurses emphasize that they need a lot of time to understand what a deaf person wants $(\mathrm{M}=3.10 ; \mathrm{SD}=1.22 ; 95 \% \mathrm{CI}=2.71-3.49)$. In $87.5 \%$ of the answers the nurses state that they don't have an interpreter when in contact with a deaf person $(\mathrm{M}=4.48 ; \mathrm{SD}=1.11 ; 95 \% \mathrm{CI}=4.12-4.83)$.

Results show that $65 \%$ of the nurses think that the communication problem is strongly pronounced immediately upon the arrival of a deaf person into the health institution. One of the problems stated in $65 \%$ of the answers of the nurses is the inability of deaf people to respond when called upon their arrival to a health institution. Regarding the understanding of messages, $40 \%$ of nurses think that deaf people have difficulties in understanding the messages. On the other hand, $57.5 \%$ of nurses emphasize that they understand the message from a deaf person. In 77.5\% they think that they are trying to listen to the end in order to better understand the message of a deaf person. $55 \%$ of the nurses emphasize the lack of visible signs that could make the moving around of the deaf people in the health institution easier.

As the main problem in the communication of nurses with deaf people, the nurses cite the inability to understand a deaf person (37.5\%). In solving these difficulties, the nurses show patience (77.5\%) and interest in the problems of the deaf (67.5\%). According to the results in $67.5 \%$, there is eye contact between nurses and the deaf people.

A lack of interest for the issues of deaf people is present with $30 \%$ of the nurses and a lack of patience $17.5 \%$. However, middle values on the Likert scale show a low level of anger $(\mathrm{M}=1.63 ; \mathrm{SD}=1.10$; $95 \% \mathrm{CI}=1.27-1.98)$, impatience $(\mathrm{M}=1.93 ; \mathrm{SD}=1.25 ; 95 \% \mathrm{CI}=1.53-2.32)$ and the lack of interest is around $(\mathrm{M}=2.25 ; \mathrm{SD}=1.41 ; 95 \% \mathrm{CI}=1.80-2.70)$. When meeting the problem of difficult communication with deaf people, $60 \%$ of the nurses feel concerned, 55\% uncomfortable, $30 \%$ insecure, $10 \%$ angry. The results show middle level concern $(\mathrm{M}=3.08 ; \mathrm{SD}=1.37$; 95\% $\mathrm{CI}=2.64-3.51)$, insecurity $(\mathrm{M}=3.10$; $\mathrm{SD}=1.55 ; 95 \% \mathrm{CI}=2.60-3.60)$, and inconvenience $(\mathrm{M}=2.68 ; \mathrm{SD}=1.31 ; 95 \% \mathrm{CI}=2.26-3.09)$.

In examining the causes of possible communication problems, it can be seen that the interest/lack of interest of the nurses for the problems of the deaf people strongly affects their patience at work, and it 
intensifies communication problems and the possibility for a deaf person to better understand the message (Table 1).

\begin{tabular}{|c|c|c|c|c|}
\hline & & $\begin{array}{c}\text { Strongly expressed } \\
\text { problems in } \\
\text { communication }\end{array}$ & $\begin{array}{l}\text { Lack of patience } \\
\text { of the nurses }\end{array}$ & $\begin{array}{c}\text { Deaf people rarely } \\
\text { understand the } \\
\text { message }\end{array}$ \\
\hline \multirow{3}{*}{$\begin{array}{l}\text { Nurses' lack } \\
\text { of interest for } \\
\text { the problems } \\
\text { of deaf people }\end{array}$} & $\mathrm{r}_{\mathrm{s}}$ & 0.395 & 0.761 & 0.404 \\
\hline & $\mathrm{r}_{\mathrm{s}}^{2 * 100}$ & $15.6 \%$ & $57.9 \%$ & $16.3 \%$ \\
\hline & $\mathrm{p}$ & 0.012 & 0.000 & 0.010 \\
\hline
\end{tabular}

Source: Author

It can be noticed that when it comes to difficulties in communication, male nurses feel more uncomfortable, worried and angry, while female nurses are more insecure. There is no significant difference in emotional reactions depending on age, sex, and level of education.

The communication between nurses and deaf people happens through showing (95.1\%), then through writing (62.5\%) and then through speech (50\%). The manual alphabet (20\%) and sign language $(12.5 \%)$ are less common ways of communication used by the nurses. Descriptive measures of ways of communication are shown in Table 2.

Table 2: Descriptive measures of ways of communication $(\mathrm{N}=40)$

\begin{tabular}{|l|c|l|c|}
\hline ways of communication & $\mathbf{M}$ & $\pm \mathbf{S D}$ & $\mathbf{9 5 \%} \mathbf{C I}$ \\
\hline showing & 4.23 & 0.73 & $3.99-4.46$ \\
\hline writing & 3.45 & 1.18 & $3.07-3.83$ \\
\hline speech & 2.95 & 1.32 & $2.53-3.37$ \\
\hline manual alphabet & 1.90 & 1.22 & $1.51-2.21$ \\
\hline sign language & 1.73 & 1.09 & $1.38-2.07$ \\
\hline same way as with other people & 2.35 & 1.42 & $1.89-2.81$ \\
\hline
\end{tabular}

Source: Author

According to the opinion of $30 \%$ of nurses, the communication with deaf people happens in the same way as it does with other people, while $60 \%$ don't agree with that statement. There is no significant difference in relation to age $(\mathrm{p}=0.103)$, sex $(\mathrm{p}=0.473)$, level of education $(\mathrm{p}=0.901)$, and the length of service $(\mathrm{p}=0.062)$.

The analysis of the perception of knowing the manual alphabet and sign language of deaf people shows a frequency of positive opinion, $62.5 \%$. In addition, $67.5 \%$ of the nurses would like to attend a course of sign language $(\mathrm{M}=3.78 ; \mathrm{SD}=1.23 ; 95 \% \mathrm{CI}=3.38-4.17)$. In order to improve the communication with deaf people, an interpreter is needed in a health institution $(\mathrm{M}=3.93 ; \mathrm{SD}=1.21$; 95\% CI=3.54-4.31). Descriptive measures of all difficulties in communication are shown in Table 3. 


\begin{tabular}{|l|l|l|l|}
\hline Table 3: Descriptive measures of difficulties in communication (N = 40) \\
\hline difficulties in communication & $\mathbf{M}$ & \pm SD & $\mathbf{9 5 \%}$ CI \\
\hline communication problem strongly expressed & 3.70 & 1.32 & $3.28-4.12$ \\
\hline deaf people are not responding & 3.78 & 1.19 & $3.40-4.15$ \\
\hline deaf people hardly understand instructions & 3.15 & 1.03 & $2.82-3.48$ \\
\hline deaf people rarely understand the message & 3.70 & 1.32 & $3.28-4.12$ \\
\hline deaf people you never look into eyes & 3.78 & 1.19 & $3.40-4.15$ \\
\hline nurses do not understand what a deaf person needs & 3.15 & 1.03 & $2.82-3.48$ \\
\hline nurses do not listen to the end deaf persons & 2.85 & 1.21 & $2.64-3.24$ \\
\hline low interest nurses to the problems of the deaf persons & 1.93 & 1.02 & $1.60-2.25$ \\
\hline low of patience nurses & 2.45 & 1.13 & $2.09-2.81$ \\
\hline no visible mark to facilitate movement in institution & 1.95 & 1.09 & $1.60-2.30$ \\
\hline communication problem strongly expressed & 2.25 & 1.41 & $1.80-2.70$ \\
\hline deaf people are not responding & 1.93 & 1.25 & $1.53-2.32$ \\
\hline Source: Author & & & \\
\hline
\end{tabular}

The connection between the perception of the nurses about the needs of these ways of communication and the willingness to attend a sign language course has been examined. The result of the Pearson coefficient $(\mathrm{r}=0.323)$ shows that the nurses who emphasize the necessity of this knowledge are also willing to attend a sign language course. The percentage of this common variations is in average $10.4 \%$ which is the coefficient of determination $(\mathrm{p}=0.042)$.

There is no difference in age, sex, level of education, or length of service on the ways of communication, emotional reactions, and the perception of the presence of an interpreter in an institution.

\section{Discussion}

When a nurse in a health institution meets a person with hearing impairment, efficient, mutually clear and understandable communication becomes a problem.

In this research, the perception of difficulties in the communication between the nurses and deaf people is significantly pronounced. The difficulties include the lack of response of deaf people when being called and the lack of understanding of messages. This research shows that the nurses mostly communicate with deaf people by showing and writing, but can't clearly assess if the deaf people have understood their message. It is interesting that some of the nurses claim to use sign language in communication, although the practical experience shows that the knowledge of sign language isn't spread among nurses. The nurses state that deaf people don't have an interpreter provided. The initiative usually comes from the deaf person. A feeling of discomfort and insecurity indicates a need for education about the ways of communication with deaf people in order to reduce the difficulties and to develop a better communication at mutual pleasure. The age, sex, level of education, and the length of nurses' service has no significant effect on the way of communication, emotional reactions and the perception of the need for an interpreter in a health institution.

Studies show that the hiding of the disability by the person with hearing impairment, the exposure of the staff to stress at work and a poor communication among the staff, as well as inadequate education and the lack of skills are the main factors for communicational problems of people with hearing impairment upon arrival to a hospital (Adib-Hajbaghery \& Rezaei-Shahsavarloo, 2015; Pribanić \& Milković, 2012). For nurses, communication with deaf people is difficult, and they sometimes need more time for the application of nursing intervention (Mattjus, 2012). The time needed for communication with deaf people is often limited by other demands the nurses have to fulfil, and considerably affects the way of communication. Due to a lack of time, the nurses sometimes avoid direct communication and they communicate with a deaf person through an intermediary, mostly a family member (Hemsley, Balandin, \& Worrall, 2012). Using family members can cause problems for patient confidentiality or in protecting the patient from dispiriting information. In a situation when they are insecure or when they haven't understood what the nurse had been saying, deaf people can 
feel uncomfortable to ask more than once to repeat the comment or the question. Moreover, difficulties in communication can result in dissatisfaction with the quality of health care (Barnett, Kuol, \& Coppola, 2014).

Limitations in communication can result in the lack of understanding of the patients' needs and a wrong assessment about patients' intelligence (Helder, 2012). Also, a significant percentage of nurses in this research are patient during the communication, but feel worried, uncomfortable and angry when they are not able to understand a deaf person.

In communicating with deaf people, nurses and other healthcare workers often apply paper writing and lip reading. They assume that this way of communication is most effective. However, this communication is insufficient, often inadequate and ineffective (Kauenburg, Fellinger, \& Fellinger, 2016). The data of researches show that deaf people can effectively recognize only $20 \%$ to $30 \%$ when lip reading or reading from the face (Pribanić \& Milković, 2012). „Lip reading“ is actually a way of guessing of the content of the spoken message according to the picture it makes on the lips and the face of the interlocutor (Kauenburg et al., 2016; Pribanić \& Milković, 2012). Lip reading and note writing are often ineffective ways of communication with the deaf and the difficult of hearing patients (McKee, Moreland, SR., \& Zazove, 2015).

Deaf people often have difficulties in communication when seeking health services due to insufficient knowledge of communicational needs and ways of adjustment to the situation (Pribanić \& Milković, 2012). A lack of visible signs of deaf people while moving around in a health institution contributes to that.

Deaf people are aware of the difficulties they have in verbal communication, due to an unclear articulation and a lack of language competence. They have difficulties in situations when the nurses don't know them and/or when they lack experience with deaf people. In addition to the difficulties in direct communication with the nurses, the biggest problem for deaf people arises in waiting rooms when being called (Pribanić \& Milković, 2012). It often happens that a nurse fails to recognize that it is a deaf person, they call the person and only when the person sees that nobody is answering, they realize it has been their name that was called. The difficulty is even bigger, when they call the people over the counter or the PA system or when the nurse is wearing a mask over the face (Pribanic \& Milković, 2012). In this research, the difficulties of the deaf are recognizable by the nurses. Nurses state that deaf people are not responding and hardly understand instructions.

Ineffective communication leads to a lack of understanding, wrong information and frustration with people with hearing impairment. This results in different reactions, for example some deaf people simply give up seeking for clear information, others express their rancor in an unpleasant way. A negativistic or angry behavior with a simultaneous projection of the mentioned onto the staff is also possible. Such reactions don't have to be observed in the context of neurotic, pathological reactions, but as a normal response to a stress situation (Ljubičić, 2014).

Deaf people prefer going to that health staff who is patient, understanding and who understands the person regardless the distorted speech and who knows the basic rules of communication with a person with hearing impairment (Hersh, 2013; Preminger, Oxenbøll, Barnett, Jensen, \& Laplante, 2015). They are satisfied when a nurse patiently listens and when, by asking additional questions, she looks for clarification of what hasn't been understandable due to bad articulation, speech or pronunciation or for the purposes of complementing (Pribanić \& Milković, 2012). Some research confirms that the communicational barriers caused the non-acceptance of health recommendations and the lack of understanding of the situation they were in (Sheppard, 2014).

Since the nurses in this study show patience and interest in the problems of deaf people, it can be assumed that they show a significant level of empathy and sensibility for the needs of these people. The sensibility of the nurses is also confirmed by the interest in the manual alphabet or sign language. If the nurses knew the manual alphabet or the sign language, they could more easily communicate with a deaf person. This is why such a way of communication is important in health institutions, especially in combination with lip reading and nonverbal forms like facial expressions and body movements (Pribanić \& Milković, 2012).

The possibility of having an interpreter in a health institution is another useful way of overcoming communicational and social difficulties of deaf people, but also of the health staff during their contact 
with them. In spite of disability rights laws and the UN Convention on the Rights of Persons with Disabilities, in many countries hospitals have no common practice to provide professional sign language interpreters. This would not only affect the improvement of the quality of communication, but also the improvement of the health care for deaf people. However, sign language in healthcare institutions is still difficult to apply. Such problems are noticed even in countries where deaf people have the legal right to effective communication when they come to health institutions (Kauenburg et al., 2016). When it comes to deaf people, the possibility to hire an interpreter of sign language in a health institution is rarely used (Pribanić \& Milković, 2012). Only 20\% of deaf people use the service of an interpreter upon arrival into a health institution (Pribanić \& Milković, 2012). The reason could be the unavailability of the interpreter. Together with the deficit of interpreters, the unsolved problem of the payment of the service of a professional interpreter is one of the most significant problems (Pribanić \& Milković, 2012). Since it is a situational need, it is possible to conclude that it would be necessary to develop translation services that would, depending on the circumstances, secure an interpreter during the care for a deaf person (Pribanić, 2012; Steinberg, Wiggins, Barmada, \& Sullivan, 2012). On the other hand, an interpreter is not continual with deaf person and it can also cause difficulties in communication. For instance, a deaf person can suffer from pain because nurse cannot understand his message and the interpreter of a deaf person is not present (Gichane, Heap, Fontes, \& London, 2017). There, where the translation services aren't developed, the hospital can look for the services of an interpreter through an agency. These services are being used if it is known that a deaf patient is going to be observed, as well as when it is completely clear that an interpreter would not only make the communication easier, but also more effective and pleasant (Pribanić, 2012). Most of the nurses in this research support the presence of an interpreter of sign language in a health institution because it can positively affect the process of message transfer. Mauffrey et al. emphasize that deaf people want to receive information in their own language. Health providers who use sign language or sign language interpreters are important for understanding deaf people's needs (Mauffrey, Berger, \& Hartemann, 2016). Nurses need to have special communication skills when working with deaf patients and to become aware of the specific communication form to provide inclusive and safe health care (Stephan \& Pinilla, 2014). However, studies show that nurses are lacking in knowledge and skills which are needed for quality communication with deaf people and patients with hearing impairments (Adib-Hajbaghery \& Rezaei-Shahsavarloo, 2015; Mattjus, 2012). In addition, studies show that an appropriate education about communication skills with deaf people would improve the nurses' knowledge and eliminate most of the communicational problems (Adib-Hajbaghery \& RezaeiShahsavarloo, 2015; Pribanić \& Milković, 2012; Velonaki et al., 2015).

Considering that different circumstances which can affect the process of communication, the role of the nurse upon the arrival of deaf people to a health institution, and in the integration and inclusion in society is extremely important. Only through clear and comprehensible communication, the contents and messages become understandable to a deaf person (Radibratović, Milutinović, \& Sindik, 2013). Effective communication makes nurses feel better during communication with patients with hearing impairments (Mattjus, 2012). Also, deaf people feel better because they have a feel of comfort and safety during health care (Mattjus, 2012). If a deaf person has understood the messages and is able to be independent because of the clear and comprehensive information, then integration and inclusion will be possible.

The limitations of this research include predominantly female nurses at the hospital. The small number of male population was insufficient to be an example with statistical significance for emotional reactions and possibly other significant factors. The participants were not followed longitudinally during their education for nursing care for deaf persons to determine the consequent change in attitude. It is necessary to include more than one hospital and health institutions on the primary level, since the deaf population often visits family physicians.

\section{Conclusion}

The nurses confirm that while communicating with deaf people, they mostly use showing and writing. The need for knowledge of sign language is also connected with the initiative to attend additional education. An interpreter in a health institution is necessary for effective communication. Signs that would make the moving around of deaf people in a health institution easier should be visible and available for deaf people. 
There is a priority need for better nurse education on the ways of communicating with deaf people. This would significantly contribute to the raise in the quality level of health care, but also the inclusion and the social integration of deaf people in society.

\section{References}

Adib-Hajbaghery, M., \& Rezaei-Shahsavarloo, Z. (2015). Nursing students' knowledge of and performance in communicating with patients with hearing impairment. Japan journal of nursing science, 12, 135-144. doi: 10.1111/jjns.12057

Barnett, D. D., Kuol, R., \& Coppola, N. (2014). Satisfaction with health care among people with hearing impairment: a survey of Medicare beneficiaries. Disability and rehabilitation, 36, 39-48. doi: 10.3109/09638288.2013.777803

Bennion, A., \& Forshaw, J. (2013). Insights from the experiences of older people with hearing impairment in the United Kingdom: recommendations for nurse-led rehabilitation. International journal of older people nursing, 8, 270-278.

Chowdhry, V., Padhi, M., Mohanty, B., \& Biswal, S. (2016). Perioperative challenges in management of a deaf and dumb patient posted for high-risk cardiac surgery. Annals of cardiac anaesthesia, 19, 564-567. doi: 10.4103/0971-9784.185567

Dickson, M., \& Magovan, R. (2014). Meeting deaf patients' communication needs. Nursing Times, 110, 12-15.

Gichane, M. W., Heap, M., Fontes, M., \& London, L. (2017). "They must understand we are people": Pregnancy and maternity service use among signing Deaf women in Cape Town. Disability and health journal, 10, 434-439. doi: 10.1016/j.dhjo.2017.03.016

Helder, N. (2012). Effective communication with patients who are deaf. Mental Health Practice, 15, 18-19. doi: http://dx.doi.org/10.7748/mhp2012.02.15.5.18.c8926

Hemsley, B., Balandin, S., \& Worrall, L. (2012). Nursing the patient with complex communication needs: time as a barrier and a facilitator to successful communication in hospital. Journal of advanced nursing, 68, 116-126. doi: 10.1111/j.13652648.2011.05722.x.

Hersh, M. (2013). Deafblind people, communication, independence, and isolation. Journal of deaf studies and deaf education, 18, 446-463. doi: 10.1093/deafed/ent022.

Hornakova, A., \& Hudakova, A. (2013). Effective communication with deaf Patients. JAHR - European Journal of Bioethics, 4, 157-166.

Kauenburg, A., Fellinger, P., \& Fellinger, J. (2016). Health Care Access Among Deaf People. Journal of deaf studies and deaf education, 21, 1-10. doi: 10.1093/deafed/env042

Ljubičić, M. (2014). Nursing care of persons with disabilities. Zadar: University of Zadar.

Mattjus, C. (2012). Nurses' experiences from communicating with hearing impaired patients. Novia University of Applied Sciences, Vassa. Retrieved from

https://publications.theseus.fi/bitstream/handle/10024/50533/Mattjus_Camilla.pdf?sequence=1 (21.04.2016)

Mauffrey, V., Berger, T., \& Hartemann, P. (2016). Qualitative survey of deaf patients concerning perception of their management by general practitioners. Sante publique, 2, 213-221.

McKee, M., Moreland, C., SR., A., \& Zazove, P. (2015). Hearing Loss: Communicating With the Patient Who Is Deaf or Hard of Hearing. Family physician essentials, 434, 24-28.

Newton, V. E., \& Shah, S. R. (2013). Improving communication with patients with a hearing impairment. Community Eye Health, 26, 6-7.

Preminger, J., Oxenbøll, M., Barnett, M., Jensen, L., \& Laplante, A. (2015). Perceptions of adults with hearing impairment regarding the promotion of trust in hearing healthcare service delivery. International journal of audiology, 54, 20-28. doi: 10.3109/14992027.2014.939776

Pribanić, L. (2012). Equality in access to information. Paper presented at the Proceedings of the expert meetings, Zagreb.

Pribanić, L., \& Milković, M. (2012). Deaf patient in the system of health protection. Croatian Journal of Public Health, 8, 525.

Radibratović, I., Milutinović, K., \& Sindik, J. (2013). Perspicuity of speech in communicating of health professionals. Nursing journal, 18(113-8). doi: doi:10.11608/sgnj.2013.18.025

Sheppard, K. (2014). Deaf adults and health care: Giving voice to their stories. Journal of the American Association of Nurse Practitioners, 26, 504-510. doi: 10.1002/2327-6924.12087.

Steinberg, A., Wiggins, E., Barmada, C., \& Sullivan, V. (2012). Deaf women: Experiences and perceptions of healthcare system access. Journal of women's health, 11, 729-741.

Stephan, K., \& Pinilla, S. (2014). Deaf patients in emergency medicine. Notfall \& Rettungsmedizin, 17, 449-462.

Velonaki, V., Kampouroglou, G., Velonaki, M., Dimakopoulou, K., Soutzi, P., \& A., K. (2015). Nurses' knowledge, attitudes and behavior toward Deaf patients. Disability and health journal, 8, 109-117. doi: 10.1016/j.dhjo.2014.08.005 